\title{
The relation between differences in level of food deprivation and dominance in food getting in the rat
}

\author{
G. J. SYME and J. S. POL.LARD \\ University of Canterbury, Christchurch, New Zealand
}

Two experiments investigated the contradictory results obtained by Ruskin \& Corman (1971) and Hsaio \& Schreiber (1968) concerning the effect of different motivation levels on measures of food-getting dominance in the laboratory rat. Using the dominance tube, Hsaio and Schreiber found that decreasing motivation of dominant animals affected competitive performance, whereas Ruskin and Corman found no change in dominance relationships in the limited access situation when increasing the motivation of subordinates. Measurement of time spent at a food truugh and the amount of food eaten showed that experimental conditions equivalent to those used by Ruskin and Corman did not change feeding behavior significantly. When these changes were effected, the measurement of food dominance by the limited access measure supported Hsaio and Schreiber's finding that dominance relationships in the rat are stable only while deprivation levels are held constant.

Stable food dominance relationships have been demonstrated between pairs of rats maintained at equal levels of deprivation in a variety of competitive situations (Schumsky \& Jones, 1966; Becker \& Flaherty, 1968; Hoyenga \& Rowe, 1969). But the evidence on the effects of varying the deprivation condition of one partner in such a relationship is contradictory. Using the dominance tube, Hsaio \& Schreiber (1968) manipulated the motivational level of their submissive animals by (1) not feeding them when they lost a competition, (2) prefeeding the dominant animal $8 \mathrm{~g}$ of food and the submissive animal $3 \mathrm{~g}$, and (3) placing the dominant animal on ad lib feeding while continuing to deprive the submissive animal. Their results showed that a relative increase in deprivation in the submissive animals was followed by a substantial improvement in competitive performance. Ruskin \& Corman (1971), however, using a limited access food hopper, found no improvement in the performance of submissive animals when they were deprived for up to $72 \mathrm{~h}$ and dominant animals were maintained on a 24-h deprivation schedule.

There are two possible explanations for the discrepancy. Either the different levels of food deprivation affected competitive behavior in the dominance tube but not in the limited access situation or the differences in level of food deprivation used by Ruskin and Corman were not large enough for any change in competitive behavior to be recorded. The first alternative would suggest that motivational factors are important in the dominance tube but not in the equally popular limited access measure. If this is the case, further analysis of each method is required if both situations are to be regarded as interchangeable measures of food dominance in the rat. If the second explanation is valid, it would demonstrate that alterations in deprivation should be accompanied by quantitative data reflecting the change in feeding behavior associated with the motivational changes. Neither Hsaio and Schreiber nor Ruskin and Corman provide such data. The present study was designed to test the second inypothesis.

In order to increase the motivation of their submissive Ss, Ruskin and Corman extended deprivation from 24 to $72 \mathrm{~h}$, while Hsaio and Schreiber provided ad lib food; but neither study presented data to show the degree to which feeding behavior was altered by these manipulations. Experiment 1 was designed to provide this information. In Experiment 2, feeding behavior in a noncompetitive situation was related to competitive behavior in the limited access situation.

\section{EXPERIMENT 1}

Subjects and Apparatus

The Ss were 8 naive male hooded rats (Otago strain N.Z.B.W.S.), 120 days old at the beginning of the experiment. Ss were housed together in a cage measuring $0.75 \times 0.33 \times$ $0.45 \mathrm{~m}$ high for 2 weeks before the experiment began and were maintained on a reversed light-dark schedule throughout. The apparatus consisted of a wooden box measuring $0.33 \times 0.33 \times 0.33 \mathrm{~m}$, with illumination provided by a $40-\mathrm{W}$ fluorescent lamp through a Plexiglas roof. A Plexiglas door formed one side of the box and allowed direct observation. A raised mesh steel floor allowed spilled food to fall out of reach of Ss. The remainder of the apparatus was painted in white semigloss. A food trough measuring $2.50 \times 8.75 \times 3.10 \mathrm{~cm}$ was attached at floor level to a side wall.

\section{Procedure}

A 24-h food-deprivation schedule was imposed, and Ss were habituated to the apparatus in pairs for $15 \mathrm{~min}$ per day for 10 days. By this time, all Ss were approaching the food trough and taking wet mash within $10 \mathrm{sec}$ of being placed in the apparatus. Individual measures were then taken of the time spent at the food trough, and the amount eaten was measured by weight gain over the $15 \cdot \mathrm{min}$ test
Table 1

Amount of Food (Grams) Eaten by Eight Rats Under Three Levels of Food Deprivation

Hours of Food Deprivation

\begin{tabular}{cccr}
$\mathrm{S}$ & 0 & 24 & 72 \\
\hline 1 & 3.5 & 5.9 & 13.9 \\
2 & 3.7 & 8.1 & 12.6 \\
3 & 1.6 & 8.1 & 8.1 \\
4 & 2.5 & 8.6 & 6.8 \\
5 & 2.8 & 8.1 & 14.3 \\
6 & 2.0 & 5.9 & 4.2 \\
7 & 5.9 & 9.5 & 14.5 \\
8 & 2.5 & 7.9 & 7.9 \\
Mean & 3.1 & 7.8 & 10.4 \\
SD & 1.3 & 1.2 & 3.7 \\
\hline
\end{tabular}

Table 2

Amount of Time Spent at Food Trough (Seconds) by Eight Rats Under Three Levels of Food Deprivation

\begin{tabular}{cccc} 
& \multicolumn{3}{c}{ Hours of Food Deprivation } \\
\cline { 2 - 4 }$S$ & 0 & 24 & 72 \\
\hline 1 & 570 & 706 & 840 \\
2 & 589 & 520 & 781 \\
3 & 267 & 784 & 817 \\
4 & 425 & 753 & 799 \\
5 & 666 & 861 & $\mathbf{8 4 9}$ \\
6 & 653 & 816 & $\mathbf{8 1 0}$ \\
7 & 746 & $\mathbf{7 9 0}$ & $\mathbf{8 5 4}$ \\
8 & 785 & 810 & $\mathbf{7 9 7}$ \\
Mean & 587.4 & 754.8 & $\mathbf{8 1 8 . 3}$ \\
SD & 159.9 & 98.6 & 24.9
\end{tabular}


Table 3

Amount of Food (Grams) Eaten in Competition Under Two Levels of Food Deprivation*

\begin{tabular}{crr} 
& \multicolumn{2}{c}{$\begin{array}{c}\text { Hours of Food } \\
\text { Deprivation }\end{array}$} \\
\cline { 2 - 2 } $\mathrm{S}$ & \multicolumn{1}{c}{0} & \multicolumn{1}{c}{24} \\
\hline 1 & 2.9 & 6.9 \\
${ }_{2}$ & 2.8 & 10.9 \\
$\mathrm{I}^{3}$ & 3.4 & 7.9 \\
4 & 2.3 & 3.9 \\
$\mathrm{C}^{5}$ & 2.1 & 12.1 \\
6 & 0.7 & 2.0 \\
$\mathrm{C}_{8}^{7}$ & 2.4 & 16.3 \\
$\mathrm{M}$ Iean & 2.3 & 7.9 \\
$\mathrm{SD}$ & 2.4 & 8.5 \\
\hline
\end{tabular}

*Brackets indicate competition pairs.

period. These measures were taken once for each of three deprivation conditions in the following order: (1) after $24 \mathrm{~h}$ food deprivation, (2) after $24 \mathrm{~h}$ ad lib food, (3) after $72 \mathrm{~h}$ food deprivation. To control for effects of social facilitation on eating behavior (Harlow, 1932), Ss were fed in pairs, the members of which remained constant throughout the experiments.

\section{Results and Discussion}

The amount of food eaten and the time spent at the food trough by each $S$ are shown in Tables 1 and 2. The Wilcoxon matched-pairs signed-ranks test showed significant differences between the amounts eaten in the $\mathrm{ad} \mathrm{lib}$ and $24 \mathrm{~h}$ conditions $(\mathrm{d}=0$, $\mathrm{p}<.01$ ) and between the ad lib and $72-h$ conditions $(d=0, p<.01)$, but not between the $24 \cdot \mathrm{h}$ and $72 \cdot \mathrm{h}$ conditions $(\mathrm{d}=5, \mathrm{p}>.05)$. The time spent at the food trough showed a similar pattern. A significant difference was found between the ad lib and 24 h conditions $(d=3$, $\mathbf{p}<.05)$ and between the ad lib and 72 -h conditions, but not between the $24 \cdot h$ and $72 \cdot h$ conditions $(d=6$, $\mathrm{p}>.05$ ).

These results suggest that $R$ uskin and Corman did not succeed in producing a significant alteration in feeding behavior, and consequently it is not surprising that their manipulation of deprivation level was not followed by a change in dominance relationships. EXPERIMENT 2

Subjects and Apparatus

The food trough was removed from the apparatus previously used to expose a $3.43-\mathrm{cm}$ hole in the same wall at floor level; this food hole gave access to a trough mounted outside the apparatus. The Ss used in the first experiment served as $S s$ for Experiment 2 .

\section{Procedure}

The Ss were given 2 days ad lib feeding to let them recover from the $72-h$ deprivation period and were then habituated to the modified apparatus for $15 \mathrm{~min}$ per day for 10 days. By this time, all Ss were reaching through the hole to eat food from the trough within $10 \mathrm{sec}$ of being placed in the apparatus. During the adaptation period, they were maintained on a 24-h deprivation schedule and were not fed in the home cage. One $\mathrm{S}$ from each pair was then placed in a cage in which food was provided ad lib for $24 \mathrm{~h}$ prior to competitive testing. The other $\mathrm{S}$ was maintained on a 24 -h deprivation schedule. For competitive testing, both members of a pair were placed in the apparatus for $15 \mathrm{~min}$ and the time spent in command of the food trough was measured. The amount caten was determined by weight gain over the $15-\mathrm{min}$ period. The deprivation conditions of the members of each pair were then reversed, and each pair was tested again in the competitive situation.

Results and Discussion

The amounts eaten and the times spent in command of the food trough under the two levels of deprivation are shown in Tables 3 and 4 . All Ss gained higher scores on both measures of competitive performance under the 24-h deprivation condition than they did under the ad lib condition. In both cases, the difference was found to be
Table 4

Amount of time Spent in Command of Food Trough (Seconds) Under Two Levels of Food Deprivation*

\begin{tabular}{|c|c|c|}
\hline \multirow[b]{2}{*}{$\mathrm{S}$} & \multicolumn{2}{|c|}{$\begin{array}{c}\text { Hours of Food } \\
\text { Deprivation }\end{array}$} \\
\hline & 0 & 24 \\
\hline$I_{2}^{1}$ & $\begin{array}{l}143 \\
273\end{array}$ & $\begin{array}{l}598 \\
638\end{array}$ \\
\hline $\mathrm{L}_{4}^{3}$ & $\begin{array}{l}305 \\
321\end{array}$ & $\begin{array}{l}546 \\
534\end{array}$ \\
\hline$\left[\begin{array}{c}5 \\
6\end{array}\right.$ & $\begin{array}{l}212 \\
248\end{array}$ & $\begin{array}{l}526 \\
490\end{array}$ \\
\hline$\complement_{8}^{7}$ & $\begin{array}{r}342 \\
55\end{array}$ & $\begin{array}{l}786 \\
550\end{array}$ \\
\hline $\begin{array}{l}\text { Mean } \\
\text { SD }\end{array}$ & $\begin{array}{r}237.3 \\
91.4\end{array}$ & $\begin{array}{r}583.4 \\
87.5\end{array}$ \\
\hline
\end{tabular}

*Brackets indicate competition pairs.

significant using the Wilcoxon matched-pairs signed-ranks test $(d=0$, $\mathbf{p}<.01)$. These results confirm the claim of Hsaio and Schreiber that a relative increase in the deprivation level of the submissive animals is followed by an improvement in competitive performance and enable us to generalize this statement to the limited access situation.

\section{REFERENCES}

BECKER, G., \& FLAHERTY, T. B. Group size as a determinant of dominance hierarchy stability in rats. Journal of Comparative \& Physiological Psychology, $1968,66,473-476$

HARLOW, H. F. Social facilitation of feeding in the albino rat. Journal of Genetic Psychology, 1932, 41, 211-221.

HOYENGA, K. T., \& ROWE, T. C Assessing social dominance in pairs of rats by measuring weight gain. Psychonomic Science, $1969,16,165$.

HSAIO, S., \& SCHREIBER, S. C. Social dominance and motivational variables in rats. Psychonomic Science, 1968,10 117-118.

RUSKIN, R. S., \& CORMAN, C. D. The effects of varying levels of deprivation on the stability of dominance-submission hierarchies. Psychonomic Science, 1971 , 23, 361-363.

SCHUMSKY, D. A., \& JONES, P. D. Reliable paired comparison dominance orders in rats. Psychological Record, $1966,16,473-478$. 